\title{
Evaluation of filamentous green algae as feedstocks for biofuel production
}

\author{
Wei Zhang ${ }^{1} \cdot$ Yonggang Zhao $^{1} \cdot$ Binjie Cui $^{1} \cdot$ Hui Wang ${ }^{1} \cdot$ Tianzhong Liu $^{1^{*}}$ \\ 1. Key Laboratory of Biofuels, Qingdao Institute of Bioenergy and Bioprocess \\ Technology, Chinese Academy of Sciences \\ No. 189 Songling Road, Qingdao, China
}

For correspondence (E-mail: liutz@ qibebt.ac.cn; Phone: 0086-532-80662735; Fax:0086$532-80662735)$

- For correspondence

E-mail: liutz@qibebt.ac.cn; Phone: 0086-532-80662735; Fax:0086-532-80662735 


\begin{abstract}
Compared with unicellular microalgae, filamentous algae have high resistance to grazerpredation and low-cost recovery in large-scale production. Green algae, as the the most diverse group of algae, included numerous filamentous genera and species. In this study, records of filamentous genera and species in green algae were firstly censused and classified. Then, seven filamentous strains subordinated in different genera were cultivated in bubbled-column to investigate their growth rate and energy moleculars (lipid and starch) capacity. Four strains including Stigeoclonium sp., Oedogonium nodulosum, Hormidium sp. and Zygnema extenue were screened out due to their robust growth. And they all could accumulate triacylglycerols and starch in their biomass, but with different capacity. After nitrogen starvation, Hormidium sp. and Oedogonium nodulosum respectively exhibited high capacity of lipid (45.38\% in dry weight) and starch (46.19\% in dry weight) accumulation, which could be of high potential as feedstocks for biodiesel and bioethanol production.
\end{abstract}

Key words: Filamenous algae; Green algae; Lipid; Starch; Hormidium

\title{
INTRODUCTION
}


Biodiesel production from oleoginous microalgae was proposed as a sustainable way resolving depleting fossil fuel supply and deteriorating environmental problems (Chisti 2007; Hu 2014). Many oleoginous algal strains were screened out as potential resources, but most of works were focused on single-cellular microalgal species, such as Scenedesmus, Chlorella, and Nannochloropsis etc (Hu et al. 2008). As reported by Wang et al. (2013a), one yellow-green filamentous species Tribonema minus was suggested to be a potential triacylglycerol resource for biodiesel production. Over 50\% of lipid content was obtained and its filamentous biomass could be harvested by dissolved air flotating without any flocculant addition. This result proved existence of oleaginous strains in filamentous algae, and therefore their good performance of high resistance to grazerpredation (Hillebrand et al. 2002; Guo et al. 2014) and low-cost recovery would make it more suitable for large-scale production.

There are numerous filamentous algal species, which have been subordinated into different class including green algae, blue-green algae and yellow-green algae etc (Graham and Wilcox 2000; Barsanti et al. 2008). Among them, the most famous is bluethe green algae Spirulina, which has been commerically cultivated in large scale for healthcare product and food additives (Zhang et al. 2015). Other wide uses of filamentous microalgae are in wastewater treatment (Liu et al. 2016a). Many species, subordinated in filamentous genera such as Spirogyra (Ozer et al. 2006; Khalaf 2008), Oedogonium (Gupta et al. 2009; Wang et al. 2013b) and Cladophora (Deng etal. 2007), were reported to have strong removal ability to different pollutants. Moreover, in some filamentous species high-value extracts also existed in large amount. Chen et al. (2016) used filamentous Trentepohlia arborum to accumulate valued $\beta$-carotene. Therefore, biomass 
production of filamentous algae should have a good future in commercial and environmental industrialization.

Green algae is the most diverse group of algae. Many famous unicellular genus such as Chlorella, Scenedesmus, Neochloris were just subordinated in it (Guiry 2012; Hu et al. 2008) and many filamentous species were also included. Whether there are oleaginous speices of filamentous green algae is of interest for microalgae biofuel due to their distinctive characteristics as mentioned before. Praveenkumar et al. [2012] investigated filamentous green algae species Stigeoclonium sp. Kutz. BUM11007 and found the lipid content could be elevated under nitrogen starvation. But few other reports have been found on the evaluation of lipid accumulation for filamentous green genera. In this study, resources of filamentous genera and species in green algae were firstly censused by websearching, of which seven filamentous strains distributed in 7 different genera were cultivated in bubbling columns to evaluate their growth rate and lipid, triacylglycerols and starch content. Results showed that two filamentous strains repectivley exhibited high producing-potential of lipids and starch in their biomass and may be used as resource for microalgae biofuel production.

\section{MATERIALS AND METHODS}

Strains and cultivation media

Stigeoclonium sp. FACHB 59, Oedogonium nodulosum FACHB 996, Hormidium sp. FACHB 70, Zygnema extenue FACHB 340, Spirogyra gracilis FACHB 354 were 
purchased from Freshwater Algae Culture Collection at the Institute of Hydrobiology (FACHB). Mougeotia genuflexa SCCAP K-0999 and Microthamnion kuetzingianum SCCAP K-1857 were from the Scandinavian Culture Collection of Algae and Protozoa (SCCAP). Tribonema minus SAG 880-3 was purchased from the Culture Collection of Algae of Gottingen University (SAG). All of them were sustained in regular BG11.

Cultivations in column photobioreactor

Column bubbling bioreactor (40 cm height, $2 \mathrm{~cm}$ diameter) containing $200 \mathrm{~mL}$ of medium was utilized to cultivate these filamentous microalgae. The fluorescent lamps was used to provide illumination and the light intersity was controlled at $100 \pm 5 \mu \mathrm{mol}$ photons $\mathrm{m}^{-2} \mathrm{~s}^{-1}$. The culture was continously bubbled with $1 \% \mathrm{CO}_{2}(\mathrm{v} / \mathrm{v})$ enriched compressed air. Regular BG11 medium was utilized for testing their growth and chemical analysis. For lipid induction cultivations under nitrogen deprivation, algal filaments cultivated in regular BG11 medium for 10 days were harvested by filtration with filtering fabric with 300 meshes and washed three times with nitrate-free BG11 medium. The the pastes were suspended in the nitrate-free BG11 medium and cultivated in bubbling columns. The light irradiance and $\mathrm{CO}_{2}$ mixed gas as the same as before were provided..

Determination of biomass density and chemical composition

Biomass density was measured according to Peng et al. (2014). A certain volume (v) of algal culture was filtered on preweighted membrane $\left(\mathrm{DW}_{0}\right)$, oven dried at $105^{\circ} \mathrm{C}$ 
overnight and then weighed as $\mathrm{DW}_{1}$. The biomass density was calculated as $\left(\mathrm{DW}_{1^{-}}\right.$ $\left.\mathrm{DW}_{0}\right) / \mathrm{v}$. The lipid content was determined by gravimetric analysis according to modified Bligh and Dyer's method (Peng et al. 2014). About $50 \mathrm{mg}$ lyophilized biomass was weighed as Wc. Then the biomass was extracted with chloroform $/$ methanol $/ 1 \% \mathrm{NaCl}$ $(2 / 2 / 1, v / v / v)$. Finally, the chloroform layer was collected, evaporated under $\mathrm{N}_{2}$, dried in a vacuum drying oven, and then weighed as $\mathrm{W}_{1}$. The lipid content was calculated as $\mathrm{W}_{1} /$ Wc. The carbonhydrate content was determined by regular phenol-sulfuric acid method as Laurens et al. (2012). For determination of protein content, the nitrogen contents in the lyophilized biomass were measured by an elemental analyzer, and then the protein concentration was obtained with the correlation factor of 4.78 (Laurens et al. 2012).

Quantification of triacylglycerols and starch

Quantification of triacylglycerol content was done usinga TLC-flame ionization detection chromatography system (Iatron Laboratories, Japan) (Chen et al. 2012). The experimental procedure was fulfilled as Peng et al. 2014. Extracted cellular lipid samples were dissolved in chloroform and then spotted onto Chromarod S-III silica-coated quartz rods. The rods were developed in two solvent system of chloroform/ acetic acid/methanol (150:60:2, v/v/v) followed by benzene/hexane (50:50, v/v). After development, the rods were oven-dried at $70{ }^{\circ} \mathrm{C}$ and then scanned in the Iatroscan analyzer.

A modified Megazyme starch assay was utilized for quantification of starch content. 30-40 mg lysophilized biomass was treated with $1.5 \mathrm{ml} 80 \%$ ethanol solution two times 
at $75^{\circ} \mathrm{C}$. The dried precipitate was pestled and re-suspended in distilled water to final volume of $10 \mathrm{ml} .0 .5 \mathrm{ml}$ homogenous solution was aspirated and treated with boiling water for $10 \mathrm{~min}$. Then $0.5 \mathrm{~mL} 200 \mathrm{mmol} / \mathrm{L} \mathrm{NaAc}(\mathrm{pH} 5.5), 6$ unit $\alpha$ amyloglucosidase(Sigma) and 0.5 unit $\alpha$-amylase(Sigma) were added into the solution. And two samples without enzyme addition and homogenous solution were provided as control. After $4 \mathrm{hr}$ treatment at $37^{\circ} \mathrm{C}$, the samples were centrifuged and the supernatants were applied on glucose quantification by Dinitro Salicylic Acid (DNS) method. The starch content was obtained by multiplying the glucose value with conversion factor of 0.9. For one biomass sample, at least 3 parellels were applied.

Fluorescence of lipid body by Nile red staining

Nile red staining (Greenspan et al., 1985) was conducted according to Wang et al. in 2013. Filaments were washed with physiological saline solution, resuspended in the solution with $0.01 \mathrm{mg} / \mathrm{L}$ Nile red and then incubated for $10 \mathrm{~min}$. After washing once, stained microalgal cells were observed by fluorescent microscopy.

Transmission electronic microscopic examination

According to Wang et al. (2013a), filaments were harvested and submerged into 1\% glutaraldehyde and then $1 \%$ osmic acid for cell fixation. The dehydration was carried out by acetone series of $30 \%, 50 \%, 70 \%, 80 \%, 90 \%$ and $95 \%$, followed by $100 \%$ acetone for 3 times. After that, the cell samples were impregnated by acetone/spur resin mixture and 
embedded into spur resin. The embedding blocks were sliced and stained by uranyl acetate. Sliced section was examined with a Hitachi H-7650 transmission electron microscope.

Statistical analysis

All experiments were done with duplicate samples and repeated at least once. All the data shown in figures, tables, and text are the mean values. The $\mathrm{P}$ values calculated using SPSS are small than 0.05 .

\section{RESULTS AND DISCUSSION}

\section{The filamentous speices in green algae}

Through web searching, it was found that there are abundant filamentous genera in group of green algae distributed widely in taxonomy. 37 filamentous green algae genera were found on NCBI taxonomy database, and their classification information were listed in Fig.1. All of them have stable branched or unbranched filaments. Some genus such as Interfilum and Stichococcus, in which unicellular and short filamentous clones exist simultaneously, weren't included. And some macro seaweed having complex-crossing filaments or rectigular form were also left out. Of these genera, 29 are classified into Chlorophyta and 7 into Streptophyta. They are distributed in five different classes including Chlorophyceae, Ulvophyceae, Trebouxiophyceae Zygnemophyceae and 
Klebsormidiophyceae except for Geminella, which are respectively classified into Chlorophyceae and Trebouxiophyceae by The Culture Collection of Algae and Protozoa (CCAP) and the Culture Collection of Algae at Goettingen University (SAG).

Chlorophyceae is the largest class in Chlorophyta and many familiar unicellular genera such as Chlamydomonas, and Haematococcus also belongs to them. 12 filamentous genera are classified into Chlorophyceae and distibuted into 4 orders except for uncertain Microspora. The Ulvophyceae includes 13 filamentous genera, which is famous for its well known seaweed members such as sea lettuce and Ulva. Three genera of Rhizoclonium, Pithophora and Cladophora in Cladophorales are sometimes taken as macro-weeds because their branched filaments are easy to aggregate into distinctive morphology in water. The other 11 filamentous genera are respectively distributed in Trebouxiophyceae (4), Zygnemophyceae (6) and Klebsormidiophyceae (1).

Resources of filamentous species were listed in Table 1. In the Algaebase, there are 5151 filamentous species nomenclature in sum, of which 2428 have been flagged as currently accepted taxonomically. Among them, Oedogonium, Cladophora and Spirogyra respectivley have 1402(519), 1071(215) and 698(516) species(accepted) records, taking the top three. And collections of filamenous green algae in four preservation organization are also concluded. In the Culture Collection of Algae and Protozoa (CCAP), SAG, SCCAP and FACHB, there are 65, 164, 31 and 27 filamentous green algae clones preserved respectivley. Although there are abundant resource of filamentous green algae, there is few of research focused on their lipid production except Stigeoclonium sp. reported by Praveenkumar et al. (2012). Haq et al. (2014) once investigated the biodiesel production from three filamentous green-algae Cladophora, 
Spirogyra and Oedogonium. Liu et al. (2016b) once investigated fatty acid profile of four filamentous green algae of Klebsormidium sp. LJ1, Klebsormidium sp. LJ2, Stigeoclonium sp. and Uronema sp.. However, there is still abscent of more detailed report about lipid producing efficiency among filamentous green algae.

\section{Growth of different filamentous strains in bubbled column photobioreator}

Seven strains distributed in 7 different filamentous green-algae genera were sustained in labscale shaking flask with a previously-reported oleoginous yellow-green filamentous species Tribonema minus as control. Supplementary Fig. 1 respectively presented their genus-specific filament phenotypes. They were distinguished with each other by their filament shape, cell size and chloroplast shape. All of them grew slowly in the flask. After one month static flask cultivation the biomass density can only reach about $0.5-1$ $\mathrm{g} / \mathrm{L}$.

Photobioreactor cultivation was thought to be an effective way to promote microalgae growth and biomass production by enhanced mixing, $\mathrm{CO}_{2}$ and light supply (Eriksen 2008). And bubbling column had been widely applied on evaluation of different microalgae species (Wang et al. 2014). So these filaments were respectively suspended in BG11 medium for bubbling column cultivation. An initial inoculation density was controlled at $0.1-0.2 \mathrm{~g} / \mathrm{L}$. After 10 days incubation, no obvious growth was observed for three filamentous strains, Spirogyra gracilis, Mougeotia genuflexa and Microthamnion kuetzingianum. While, the other 4 strains, Stigeoclonium sp., Oedogonium nodulosum, Hormidium sp., and Zygnema extenue grew well as Tribonema minus, as shown in Fig. 2. 
The averaged biomass productivity after 10 days cultivation are $0.35,0.45,0.38$ and 0.33

$\mathrm{g} \mathrm{L}^{-1}$ day $^{-1}$ Respectively. The control of Tribonema minus has the growth rate of $0.42 \mathrm{~g}$

$\mathrm{L}^{-1}$ day $^{-1}$, comformed with the report by Wang et al (2014). Their grwoth rates are much higher than Stigeoclonium sp. in hoffkins flask, 2.5-3 g/L biomass density after about 1 month cultivation by Praveenkumar et al. (2012).

Unsimilar with well dispersed unicellular microalgae in bubbling column, the disperity of filaments in medium will influence the photosynthetic grwoth of filamentous microalgae. In this work, filaments of Stigeoclonium sp., Oedogonium nodulosum, and Hormidium sp. were dispersed well in single silk in bubbling column. However the filaments of Zygnema are usually curled into small granules with the diameter of $2-4 \mathrm{~mm}$, that caused its relatively lower biomass productivity. While M.genuflexa and S.gracilis, belonging to the same family of Zygnemataceae as Zygnema, are usually ruptured into short section by aerated bubbles, which contributed to their inhibited growth.

M.kuetzingianum has slim and branched filaments, which often clustered into small granule in flask or bubbling column. And these small clustered granule couldn't obtain effectively growth in bubbled photobioreactor. On the view of mass cultivation, those filamentous green microalgae with resistance to rupture and to curl into granules would be more suitable to cultivate in bubbled photobioreactor.

\section{Difference of chemical composition}

Table 2 showed the chemical compostion of the biomass after 10 days cultivation of Stigeoclonium sp., Oedogonium nodulosum, Hormidium sp., and Zygnema extenue with 
the control Tribonema minus. Their protein contents in the biomass were similar. Great difference was identified among their carbohydrate and lipid content. And triacylglycerols and starch, as two principal storages of chemical energy, were simmultaneously detected in all of the four green-algae strains with different capacity. Among four robust green-algae, Hormidium sp. exhibited the highest lipid (26.83\%) and triacyglycerol (11.02\%) content, but still far lower than $49.44 \%$ and $40.52 \%$ of Tribonema minus. As reported by Guo et al. in 2014, Tribonema minus prefered to accumulate high content of lipids in biomass under nitrogen completion. However, in most of unicellular oleaginous green-algae such as Scenedesmus and Chlorella, high lipid content could always be coupled with growth-limitation induced by nitrogen starvation (Hu et al. 2008). Praveenkumar et al. (2012) also reported 13.8\% of content in Stigeoclonium $s p$. under nutrent completionunder nutrent completion, and 3 times increase of lipid content after nitrogen starvation. Therefore, these four strains may have an higher lipid-producing capacity under nitrogen limitation.

In green-algae, starch together with triacylglycerols are principal storages of chemical energy, and algal starch as a fermentable substrate could be utilized for bioethanol production (Hirayama et al. 1998; Zachleder and Brányiková 2014). In Table 2, Oedogonium nodulosum showed higher starch-accumulating capacity (30.92\% in DW) than the other 3 strains. And it also exhibited the highest carbohydrate (64.27\%) content in its biomass, but with the lowest lipid (14.06\%) and triacylglycerol (4.78\%) contents. It seemed that, Oedogonium nodulosum tend to synthesize starch instead of triacylglyerols. In the genera of Chlamydomonas, Chlorella and Scenedesmus with many oleaginous strains, many starch-rich strains were also reported (Zachleder and Brányiková 2014), so 
the choice of starch or triacylglycerols as reservoir was thought to be a species-specific instead of genus-specific (Hu et al. 2008). Nitrengen deprivation has been verified as an induction process for high starch accumulation (Zachleder and Brányiková 2014), while it's found in one green-algae Pseudochlorococcum sp. that, cells tended to shift the carbon partitioning from starch into neutral lipid under nitrogen starvation. So it's necessary to evaluate starch or triacylglycerol producing-potentials through a nitrogendeprivation process in these four green-algae strains.

\section{Accumulation of biomass, lipids and starch under nitrogen starvation}

To evaluate potential of four filamentous green algae Stigeoclonium sp., Oedogonium nodulosum, Hormidium sp., and Zygnema extenue, their filaments were supspended in BG11 without any addition of nitrate. The inoculum density was controlled at relatively higher density $\left(0.75-1 \mathrm{~g} \mathrm{~L}^{-1}\right)$. Fig. 3. A revealed an obvious biomass proliferration of all these four strains. After 10 days incubation, the biomass density could reached 2.24-4.82 $\mathrm{g} \mathrm{L}^{-1}$. In one oleaginous microalgae Nannochloropsis oculata, a second-step nitrogen-deprivation process was once applied to increase its lipid content, and an increase of biomass concentration was accompanied (Su et al. 2011). This induction growth coupled with lipid accumulation was also reported in Phaedactylum tricornutum and found to require an abundant carbon supply (Peng et al. 2014). In these four filamentous strains, the similar biomass production under nitrogen starvation was also coupled with the change of their cellular composition as shown in Fig. 3. 
Fig. 3. B showed lipid content change after nitrogen starvation. In Hormidium sp. and Zygnema extenue, their cellular lipid contents were respectively increased from $26.41 \%$ and $22.48 \%$ to $45.38 \%$ and $30.96 \%$ in dry weight (DW) after 10 days incubation. While in the other two strains, there was none of any obvious increase of lipid content identified. In the statistic analysis by Hu et al. (2008), oleaginous green algae respectively have an average $25.5 \%$ and $45.7 \%$ lipid content under optimal and unfavorable nutrientdeplete condition. Hormidium sp. in this study just reached the oleaginous level. And in this induction process Hormidium sp. gave a lipid accumulation rate of $0.141 \mathrm{~g} \mathrm{~g}^{-1} \mathrm{day}^{-1}$, close to $0.154 \mathrm{~g} \mathrm{~g}^{-1}$ day $^{-1}$ in Nannochloropsis oculata reported by Su et al. in 2011. So Hormidium sp. approached to be a potential oleaginous filamentous strain utilized for biodiesel production.

Triacylglycerol accumulation in response to nitrogen starvation is well-know in different green algae, such as Chlamydomonas (Boyle et al. 2012; Goncalves et al. 2016), Scenedesmus (Breuer et al. 2012; Breuer et al. 2013), Chlorella (Breuer et al. 2012; Goncalves et al. 2013). During the process, the chlorophyll content decreases, phospholipids and glycolipids are hydrolyzed, photosynthetic membranes are degraded, and oil droplets are formed in microalgal cells (Peng et al. 2014). Fig. 3. C also revealed similar process in all of these four filamentous strains. More triacylglycerols were synthesized and dominated in total cellular lipids instead of polar membrane lipids. After 10 days nitrogen-deprivation, the triacylglycerol contents of Oedogonium nodulosum, Stigeoclonium sp., Zygnema extenue and Hormidium sp. was elevated respectivley from $2.17 \%, 6.27 \%, 2.24 \%$ and $9.64 \%$ to $4.40 \%, 11.80 \%, 19.48 \%$ and $30.69 \%$. These neutral lipids gathered and form into overt oil droplets, which were identified in these filaments 
by Nile red staining microscopy in Supplementary Fig. 2. In Chlamydomonas, three types of acyltransferases were found to be upregulated in response to nitrogen starvation (Boyle et al. 2012). And a phospholipid:diacylglycerol acyltransferase was proved to be involved in membrane degradation and triacylglycerol synthesis in Chlamydomonas reinhardtii (Yoon et al. 2012). So in these filamentous green algae, triacylglycerol synthesis should also be a similar reglulated process in response to nitrogen starvation.

Fig. 3. D showed accumulation of starch was also enhanced in these filaments after nitrogen starvation. In Oedogonium nodulosum and Stigeoclonium sp., 1.33 (from $34.66 \%$ to $46.19 \%$ in DW) and 2.10 times (from $17.92 \%$ to $37.66 \%$ in DW) increase of starch content was detected after nitrogen starvation. In Chlamydomonas reinhardtii, starch content up to $45 \%$ of cell dry weight and triacylglycerol cotent below $5 \%$ was also reported (Li et al. 2010). Considering that similar low triacylglycerol content $(7.70 \%$ and $11.80 \%$ in DW) in these two filamentous strains, they should belong to starch-rich species and were more suitable as feedstocks for bioethanol production.

In all of the four filarmentous strains, starch accumulated under nitrogen starvation. In oleaginous Hormidium sp., its starch content increased from $8.45 \%$ to $22.01 \%$. In green algae, triacylglycerols and starch compete for carbon precursors, and there has always been a hypothesis that blocked starch synthesis would enhance triacylglycerol accumulation in cells ( $\mathrm{Li}$ et al. 2010). It was just proved by the report by Li et al. in 2010, that one starchless Chlamydomonas mutant could accumulate about $20 \%$ triacylglycerol in DW, 10 times as wild strain. And the similar work was also fulfilled in a oleaginous Scenedesmu obliquus by de Jaeger et al.(2014). The starchless Scenedesmus mutant was found to have 57\% triacylglycerol content (Breuer et al. 2014). Therefore, a starchless 
Hormidium sp. may be a promising filamentous strain for biodiesel production, if weakened starch synthesis could be appled similarly through genetic modification.

\section{CONCLUSION}

In green algae, there was abundant filamentous resource with good potential as resource for bioenergy production. Four filamentous green algae strains including Stigeoclonium sp., Oedogonium nodulosum, Hormidium sp. and Zygnema extenue could grow robustly in bubbled column photobioreactor. And under nitrogen starvation, they accumulated triacylglyercols and starch simultaneously in filaments, just similar as unicellular green algae species. Hormidium sp. and Oedogonium nodulosum respectively exhibited high potentials of triacylglycerols and starch production. For biodiesel production, weakened starch synthesis in Hormidium sp. through genetic modification may create a promising filamentous strain with high lipid productivity.

\section{ACKNOWLEDGMENT}

This work was supported by 2016 Sino-Thai Cooperation Project from the National Science Foundation of China (Grant No. 51561145015) and National key R\&D program from Ministry of Science and Technology of China(Grant No. 2016YFB0601001-02). Thanks for generous providing of filamentous strains by Prof. Song Lirong in Institute of Hydrobiology, Chinese Academy of Sciences.

\section{REFERENCES}


1. Barsanti, L., Coltelli, P., Evangelista, V., Frassanito, A.M., Passarelli, V., Vesentini, N., Gualtieri, P. 2008. The world of algae. Algal Toxins: Nature, Occurrence, Effect and Detection, 1-15.

2. Boyle, N.R., Page, M.D., Liu, B.S., Blaby, I.K., Casero, D., Kropat, J., Cokus, S.J., Hong-Hermesdorf, A., Shaw, J., Karpowicz, S.J., Gallaher, S.D., Johnson, S., Benning, C., Pellegrini, M., Grossman, A., Merchant, S.S. 2012. Three Acyltransferases and Nitrogen-responsive Regulator Are Implicated in Nitrogen Starvation-induced Triacylglycerol Accumulation in Chlamydomonas. Journal of Biological Chemistry, 287(19), 15811-15825.

3. Breuer, G., Lamers, P.P., Martens, D.E., Draaisma, R.B., Wijffels, R.H. 2012. The impact of nitrogen starvation on the dynamics of triacylglycerol accumulation in nine microalgae strains. Bioresour Technol, 124, 217-226.

4. Breuer, G., Lamers, P.P., Martens, D.E., Draaisma, R.B., Wijffels, R.H. 2013. Effect of light intensity, $\mathrm{pH}$, and temperature on triacylglycerol (TAG) accumulation induced by nitrogen starvation in Scenedesmus obliquus. Bioresour Technol, 143, 1-9.

5. Breuer, G., de Jaeger, L., Artus, V.P.G., Martens, D.E., Springer, J., Draaisma, R.B., Eggink, G., Wijffels, R.H., Lamers, P.P. 2014. Superior triacylglycerol (TAG) accumulation in starchless mutants of Scenedesmus obliquus: (II) evaluation of TAG yield and productivity in controlled photobioreactors. Biotechnol Biofuels, 7.

6. Busi, M.V., Barchiesi, J., Martin, M., Gomez-Casati, D.F. 2014. Starch metabolism in green algae. Starch-Starke, 66(1-2), 28-40. 
7. Chen, L., Liu, T., Zhang, W., Chen, X., Wang, J. 2012. Biodiesel production from algae oil high in free fatty acids by two-step catalytic conversion. Bioresour Technol, $111,208-14$.

8. Chen, L., Zhang, L., Liu, T. 2016. Concurrent production of carotenoids and lipid by a filamentous microalga Trentepohlia arborum. Bioresour Technol, 214, 567-73.

9. Chisti, Y. 2007. Biodiesel from microalgae. Biotechnol Adv, 25(3), 294-306.

10. de Jaeger, L., Verbeek, R.E.M., Draaisma, R.B., Martens, D.E., Springer, J., Eggink, G., Wijffels, R.H. 2014. Superior triacylglycerol (TAG) accumulation in starchless mutants of Scenedesmus obliquus: (I) mutant generation and characterization. Biotechnol Biofuels, 7.

11. Deng, L.P., Su, Y.Y., Hua, S., Wang, X.T., Zhu, X.B. 2007. Sorption and desorption of lead (II) from wastewater by green algae Cladophora fascicularis. J Hazard Mater, $143(1-2), 220-225$.

12. Eriksen, N.T. 2008. The technology of microalgal culturing. Biotechnol Lett, 30(9), $1525-1536$.

13. Goncalves, E.C., Johnson, J.V., Rathinasabapathi, B. 2013. Conversion of membrane lipid acyl groups to triacylglycerol and formation of lipid bodies upon nitrogen starvation in biofuel green algae Chlorella UTEX29. Planta, 238(5), 895-906.

14. Goncalves, E.C., Koh, J., Zhu, N., Yoo, M.J., Chen, S.X., Matsuo, T., Johnson, J.V., Rathinasabapathi, B. 2016. Nitrogen starvation-induced accumulation of triacylglycerol in the green algae: evidence for a role for ROC40, a transcription factor involved in circadian rhythm. Plant Journal, 85(6), 743-757.

15. Graham, L., Wilcox, L., 2000. Algae. Prentice-Hall 
16. Greenspan, P., Mayer, E.P., Fowler, S.D. 1985. Nile Red - a Selective Fluorescent Stain for Intracellular Lipid Droplets. Journal of Cell Biology, 100(3), 965-973.

17. Guiry, M.D. 2012. How Many Species of Algae Are There? Journal of Phycology, 48(5), 1057-1063.

18. Guo, F.J., Wang, H., Wang, J.F., Zhou, W.J., Gao, L.L., Chen, L., Dong, Q.Z., Zhang, W., Liu, T.Z. 2014. Special biochemical responses to nitrogen deprivation of filamentous oleaginous microalgae Tribonema sp. Bioresour Technol, 158, 19-24. 19. Gupta, V.K., Rastogi, A. 2009. Biosorption of hexavalent chromium by raw and acid-treated green alga Oedogonium hatei from aqueous solutions. J Hazard Mater, 163(1), 396-402.

20. Haq, I., Muhammad, A., Hameed, U. 2014. Comparative assessment of Cladophora, Spirogyra and Oedogonium biomass for the production of fatty acid methyl esters. Applied Biochemistry and Microbiology, 50(1), 69-72.

21. Hillebrand, H., Kahlert, M., Haglund, A.L., Berninger, U.G., Nagel, S., Wickham, S. 2002. Control of microbenthic communities by grazing and nutrient supply. Ecology, 83(8), 2205-2219.

22. Hirayama, S., Ueda, R., Ogushi, Y., Hirano, A., Samejima, Y., Hon-Nami, K., Kunito, S. 1998. Ethanol production from carbon dioxide by fermentative microalgae. Advances in Chemical Conversions for Mitigating Carbon Dioxide, 114, 657-660. 23. Hu, Q., Sommerfeld, M., Jarvis, E., Ghirardi, M., Posewitz, M., Seibert, M., Darzins, A. 2008. Microalgal triacylglycerols as feedstocks for biofuel production: perspectives and advances. Plant Journal, 54(4), 621-639. 
24. Hu, Q. 2014. Progress and perspectives on microalgal mass culture. Algal ResearchBiomass Biofuels and Bioproducts, 4, 1-1.

25. Khalaf, M.A. 2008. Biosorption of reactive dye from textile wastewater by nonviable biomass of Aspergillus niger and Spirogyra sp. Bioresour Technol, 99(14), 66316634.

26. Laurens, L.M.L., Dempster, T.A., Jones, H.D.T., Wolfrum, E.J., Van Wychen, S., McAllister, J.S.P., Rencenberger, M., Parcher, K.J., Gloe, L.M. 2012. Algal Biomass Constituent Analysis: Method Uncertainties and Investigation of the Underlying Measuring Chemistries. Anal Chem, 84(4), 1879-1887.

27. Li, Y.T., Han, D.X., Hu, G.R., Dauvillee, D., Sommerfeld, M., Ball, S., Hua, Q. 2010. Chlamydomonas starchless mutant defective in ADP-glucose pyrophosphorylase hyper-accumulates triacylglycerol. Metab Eng, 12(4), 387-391.

28. Li, Y.T., Han, D.X., Sommerfeld, M., Hu, Q.A. 2011. Photosynthetic carbon partitioning and lipid production in the oleaginous microalga Pseudochlorococcum sp. (Chlorophyceae) under nitrogen-limited conditions. Bioresour Technol, 102(1), 123-129. 29. Liu, J.Z., Danneels, B., Vanormelingen, P., Vyverman, W. 2016a. Nutrient removal from horticultural wastewater by benthic filamentous algae Klebsormidium sp., Stigeoclonium $s p$. and their communities: From laboratory flask to outdoor Algal Turf Scrubber (ATS). Water Research, 92, 61-68.

30. Liu, J.Z., Vanormelingen, P., Vyverman, W. 2016b. Fatty acid profiles of four filamentous green algae under varying culture conditions. Bioresour Technol, 200, 10801084. 
31. Ozer, A., Akkaya, G., Turabik, M. 2006. The removal of Acid Red 274 from wastewater: Combined biosorption and biocoagulation with Spirogyra rhizopus. Dyes and Pigments, 71(2), 83-89.

32. Peng, X.W., Liu, S., Zhang, W., Zhao, Y.G., Chen, L., Wang, H., Liu, T.Z. 2014. Triacylglycerol accumulation of Phaeodactylum tricornutum with different supply of inorganic carbon. Journal of Applied Phycology, 26(1), 131-139.

33. Praveenkumar, R., Johncy, K., MubarakAli, D., Vijayan, D., Thajuddin, N., Gunasekaran, M. 2012. Demonstration of Increased Lipid Accumulation Potential of Stigeoclonium sp., Kutz. BUM11007 Under Nitrogen Starved Regime: A New Source of Lipids for Biodiesel Production. Journal of Biobased Materials and Bioenergy, 6(2), 209213.

34. Su, C.H., Chien, L.J., Gomes, J., Lin, Y.S., Yu, Y.K., Liou, J.S., Syu, R.J. 2011. Factors affecting lipid accumulation by Nannochloropsis oculata in a two-stage cultivation process. Journal of Applied Phycology, 23(5), 903-908.

35. Wang, H., Gao, L.L., Chen, L., Guo, F.J., Liu, T.Z. 2013a. Integration process of biodiesel production from filamentous oleaginous microalgae Tribonema minus. Bioresour Technol, 142, 39-44.

36. Wang, H., Ji, B., Wang, J.F., Guo, F.J., Zhou, W.J., Gao, L.L., Liu, T.Z. 2014. Growth and biochemical composition of filamentous microalgae Tribonema sp. as potential biofuel feedstock. Bioprocess and Biosystems Engineering, 37(12), 2607-2613. 37. Wang, H.P., Hu, Z.Q., Xiao, B., Cheng, Q.P., Li, F.H. 2013b. Ammonium nitrogen removal in batch cultures treating digested piggery wastewater with microalgae Oedogonium sp. Water Science and Technology, 68(2), 269-275. 
38. Yoon, K., Han, D.X., Li, Y.T., Sommerfeld, M., Hu, Q. 2012.

Phospholipid:Diacylglycerol Acyltransferase Is a Multifunctional Enzyme Involved in Membrane Lipid Turnover and Degradation While Synthesizing Triacylglycerol in the Unicellular Green Microalga Chlamydomonas reinhardtii. Plant Cell, 24(9), 3708-3724.

39. Zachleder, V., Brányiková, I. 2014. Starch Overproduction by Means of Algae. in: Algal Biorefineries: Volume 1: Cultivation of Cells and Products, (Eds.) R. Bajpai, A. Prokop, M. Zappi, Springer Netherlands. Dordrecht, pp. 217-240.

40. Zhang, L.L., Chen, L., Wang, J.F., Chen, Y., Gao, X., Zhang, Z.H., Liu, T.Z. 2015. Attached cultivation for improving the biomass productivity of Spirulina platensis. Bioresour Technol, 181, 136-142. 


\section{Table 1 Species resource in filamentous green algae genera}

\begin{tabular}{|c|c|c|c|c|c|}
\hline Genus name & $\begin{array}{c}\text { Species in } \\
\text { AlgaeBase }^{+}\end{array}$ & $\begin{array}{l}\text { Number of } \\
\text { stored clones } \\
\text { in } \mathrm{CCAP}^{++}\end{array}$ & $\begin{array}{l}\text { Number of } \\
\text { stored clones } \\
\text { in } \mathrm{SAG}^{++}\end{array}$ & $\begin{array}{l}\text { Number of } \\
\text { stored clones } \\
\text { in } \mathrm{SCCAP}^{++}\end{array}$ & $\begin{array}{l}\text { Number of } \\
\text { stored clones } \\
\text { in FACHB }{ }^{++}\end{array}$ \\
\hline Geminella & $21(10)$ & 2 & 15 & 0 & 0 \\
\hline Stigeoclonium & $77(43)$ & 7 & 17 & 4 & 6 \\
\hline Chaetophora & $32(8)$ & 2 & 4 & 0 & 0 \\
\hline Aphanochaete & 24(7) & 0 & 11 & 1 & 0 \\
\hline Dilabifilum & $4(3)$ & 1 & 15 & 0 & 0 \\
\hline Draparnaldia & $37(11)$ & 3 & 0 & 1 & 0 \\
\hline Schizomeris & $2(2)$ & 0 & 3 & 1 & 0 \\
\hline Cylindrocapsa & $7(6)$ & 1 & 5 & 0 & 0 \\
\hline Oedogonium & $1402(519)$ & 3 & 5 & 4 & 12 \\
\hline Oedocladium & $16(15)$ & 1 & 0 & 0 & 0 \\
\hline Bulbochaete & $181(125)$ & 0 & 0 & 0 & 0 \\
\hline Sphaeroplea & 24(8) & 0 & 2 & 0 & 0 \\
\hline Microspora & $34(24)$ & 4 & 2 & 0 & 0 \\
\hline Urospora & $41(14)$ & 0 & 0 & 0 & 0 \\
\hline Acrosiphonia & $43(13)$ & 0 & 1 & 1 & 0 \\
\hline Trentepohlia & $149(51)$ & 2 & 4 & 1 & 0 \\
\hline Ulothrix & $202(40)$ & 5 & 6 & 1 & 0 \\
\hline Eugomontia & $2(2)$ & 0 & 0 & 0 & 0 \\
\hline Gloeotilopsis & $4(4)$ & 0 & 4 & 0 & 0 \\
\hline Gomontia & $12(8)$ & 0 & 0 & 0 & 0 \\
\hline Trichosarcina & $2(2)$ & 0 & 5 & 0 & 0 \\
\hline Cloniophora & $8(6)$ & 0 & 0 & 0 & 0 \\
\hline Pseudendoclonium & 19(9) & 3 & 2 & 5 & 0 \\
\hline Rhizoclonium & $79(32)$ & 0 & 0 & 0 & 0 \\
\hline Cladophora & $1071(215)$ & 2 & 0 & 1 & 0 \\
\hline Pithophora & 24(1) & 1 & 1 & 0 & 0 \\
\hline Gloeotila & $28(21)$ & 0 & 4 & 0 & 0 \\
\hline Planctonema & $2(1)$ & 0 & 2 & 1 & 0 \\
\hline Radiofilum & $9(3)$ & 0 & 2 & 0 & 0 \\
\hline Microthamnion & $9(5)$ & 4 & 3 & 2 & 0 \\
\hline Zygnema & $453(195)$ & 3 & 9 & 3 & 1 \\
\hline Mougeotia & 218(169) & 2 & 3 & 2 & 0 \\
\hline Spirogyra & $698(516)$ & 4 & 2 & 2 & 4 \\
\hline Sirogonium & $32(22)$ & 0 & 0 & 0 & 0 \\
\hline Zygnemopsis & $69(55)$ & 0 & 0 & 0 & 0 \\
\hline Zygogonium & $86(22)$ & 0 & 0 & 0 & 0 \\
\hline $\begin{array}{c}\text { Klebsormidium } \\
\text { (Hormidium) }\end{array}$ & $30(18)$ & 15 & 37 & 1 & 4 \\
\hline The Sum & $5151(2428)$ & 65 & 164 & 31 & 27 \\
\hline
\end{tabular}

+ AlgaeBase, A database of information on algae ( http://www.algaebase.org/)

++ CCAP, The Culture Collection of Algae and Protozoa (http://www.ccap.ac.uk/); SAG, The Culture

Collection of Algae at Goettingen University (http://www.uni-goettingen.de/en/184982.html); SCCAP, The

Scandinavian Culture Collection of Algae and Protozoa (http://www.sccap.dk/); FACHB, The Freshwater

Algae Culture Collection at the Institute of Hydrobiology (http://algae.ihb.ac.cn/English/) 


\section{Table 2 Chemical composition after 10 days cultivation in BG11}

\begin{tabular}{lccccc}
\hline & $\begin{array}{c}\text { Lipid Content } \\
(\%)\end{array}$ & $\begin{array}{c}\text { Carbohydrate } \\
\text { Content }(\%)\end{array}$ & $\begin{array}{c}\text { Protein Content } \\
(\%)\end{array}$ & $\begin{array}{c}\text { TAG } \\
\text { Content }(\%)\end{array}$ & $\begin{array}{c}\text { Starch } \\
\text { Content }(\%)\end{array}$ \\
\hline Tribonema minus & $49.44 \pm 0.62$ & $28.68 \pm 0.98$ & $19.07 \pm 0.56$ & $40.52 \pm 0.42$ & 0 \\
Stigeoclonium sp. & $18.61 \pm 2.82$ & $43.35 \pm 0.05$ & $17.79 \pm 0.58$ & $6.27 \pm 1.14$ & $17.92 \pm 1.22$ \\
Oedogonium nodulosum & $14.06 \pm 0.70$ & $64.37 \pm 0.69$ & $18.63 \pm 0.19$ & $4.78 \pm 0.09$ & $30.92 \pm 1.79$ \\
Hormidium sp. & $26.83 \pm 0.95$ & $32.47 \pm 0.44$ & $20.31 \pm 0.14$ & $11.02 \pm 0.2$ & $7.72 \pm 0.51$ \\
Zygnema extenue & $22.48 \pm 0.79$ & $46.00 \pm 2.00$ & $18.46 \pm 0.55$ & $6.26 \pm 1.11$ & $24.29 \pm 0.56$ \\
\hline
\end{tabular}

* Mean values of duplicate samples are shown with standard deviation. 


\section{Caption of Figures}

Fig. 1 Classification of 37 filamentous green algae genera

Fig. 2 Growth curves in column photobioreactor of Zygnema extenue, Oedogonium nodulosum, Stigeoclonium sp., Hormidium sp. and Tribonema minus. Mean values of duplicate samples are shown with error bars indicating standard deviation.

Fig. 3 Change of biomass density(A), contents of lipids(B), triacylglycerols(C) and starch (D) in the culture of Zygnema extenue, Oedogonium nodulosum, Stigeoclonium sp., and Hormidium sp. after 10 days incubation under nitrogen starvation. Mean values of duplicate samples are shown with error bars indicating standard deviation.

\section{Caption of Supplementary Figures}

Supplementary Fig. 1 Filament morphologies of Spirogyra gracilis, Zygnema extenue, Oedogonium nodulosum, Stigeoclonium sp., Hormidium sp., Mougeotia genuflexa, Microthamnion kuetzingianum, Tribonema minus. All scale bar in photographes represent $20 \mu \mathrm{m}$.

Supplementary Fig. 2 Nile red fluorescence of lipid body in filaments of Stigeoclonium sp., Oedogonium nodulosum, Hormidium sp., and Zygnema extenue. All scale bar in photographes represent $10 \mu \mathrm{m}$. 


\section{Figure 1}

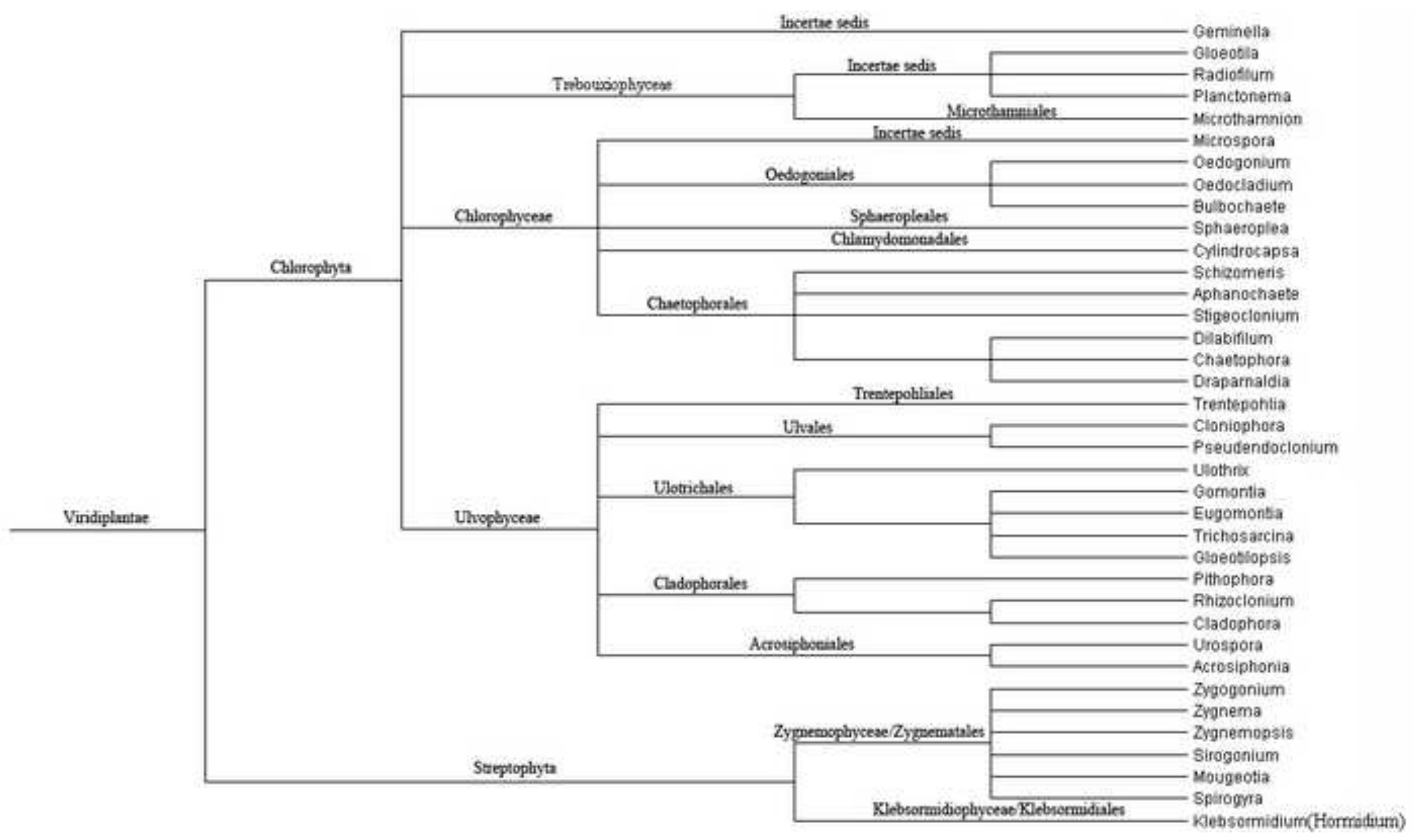




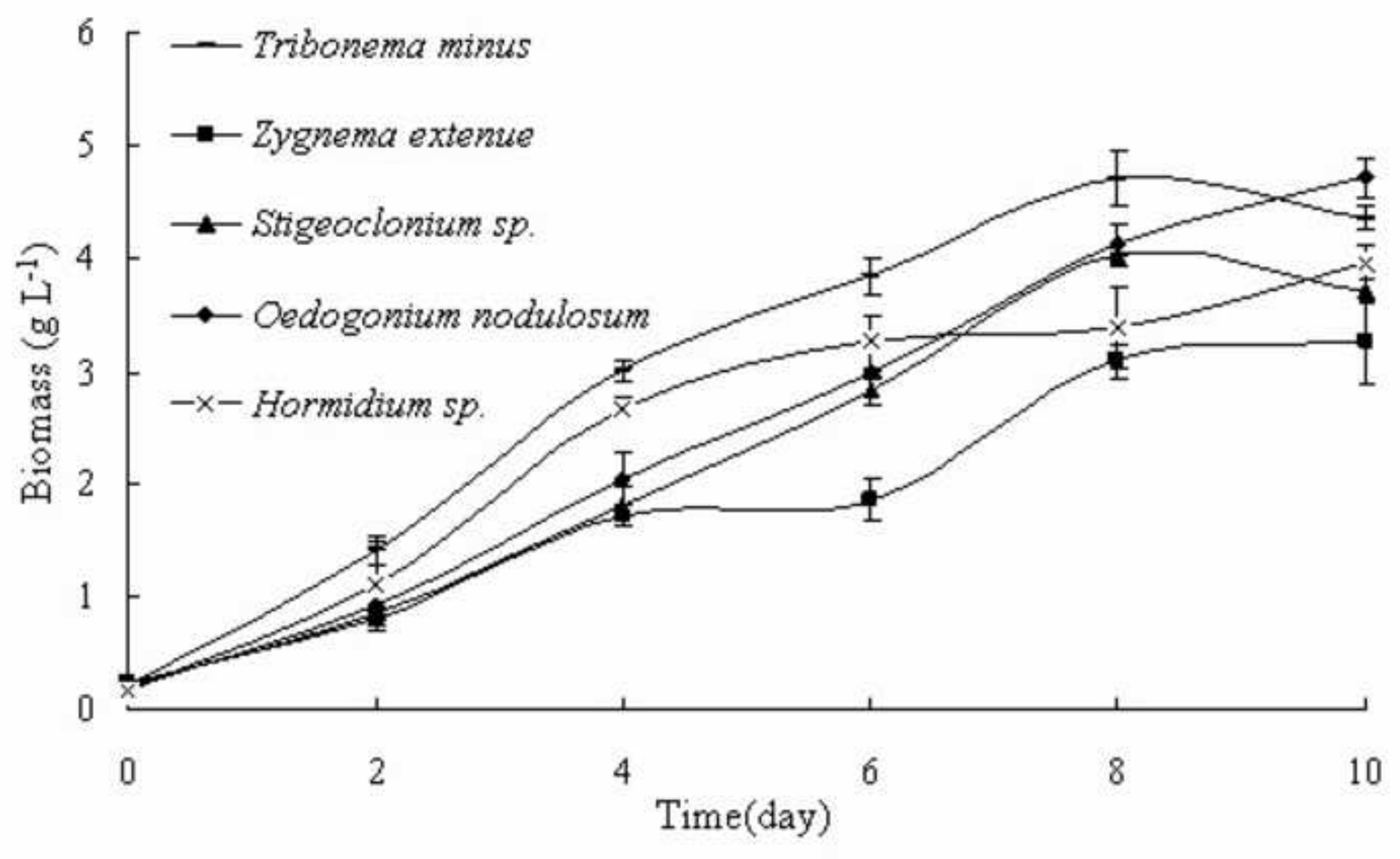

